\title{
Program of integrated development of transport infrastructure of Tyumen
}

\author{
Artur Petrov ${ }^{1, *}$ and Vera Svistunova ${ }^{1}$ \\ ${ }^{1}$ Tyumen Industrial University, Melnikaite street, 72-236, Tyumen, Russia
}

\begin{abstract}
The article discusses the feasibility of the development of urban transport and technological systems through the development of Programs for the integrated development of transport infrastructure (PIDTI). PIDTI, being one of the many regulatory documents for urban development, is intended to create some kind of a planned basis for this development. The problem is that during the development and subsequent practical implementation of this strategic document, trends in changes in the lifestyle of citizens, potential ways of their livelihoods, financial and economic support, and just the stylistic features of public and private life are not taken into account. PIDTI developers often assume that in 20 years, the life of the city will be exactly the same as today, only all of its characteristics will increase quantitatively by $20-150 \%$ (depending on the strategy option). The works of such serious researchers as S.B. Pereslegin refutes this opinion. The experience of automobilization of Russian cities also speaks about this. Today, PIDTI performs the function of the ITS General Plans of cities of the Soviet period. In this regard, the issue of the ability of PIDTI to solve the problems of the functioning of a city as a living social and technological organism in future periods becomes very serious. The article discusses this issue at the intersection of the opinions of professionals and city residents.
\end{abstract}

\section{Introduction}

Proper city management is a daunting task with the often vague formulation of the objective function, a set of input variables, and a cybernetic "black box" identifying the current processes of city life. Numerous attempts to create exact structural-functional models of cities in most cases were either unsuccessful [1-2], or extremely limited in content [3]. This is explained in different ways. Some authors [4, 5] indicate that it is almost impossible to correctly predict the characteristics of the dynamics of the development of an urban area. Others $[6,7]$ say that the dominant factors determining the future of a city are a poorly controlled factor in the socio-economic diversification of the status of a city. Many experts $[8,9]$ are confident that technological innovations affect the fate of the city. If we compare a city to a living organism, then the municipal transport and technological system performs the function of metabolism. It is transport that carries out the functions of movement in the space of an urban area of human and material flows, and the

\footnotetext{
${ }^{*}$ Corresponding author: ArtIgPetrov@yandex.ru
} 
transport infrastructure is the limiting power and speed of this movement. In this regard, the fundamental question arises about the need for the optimal structuring of transport systems and the stimulation (or limitation) of their development in certain directions. Today in the Russian Federation this issue is resolved in a regulatory way, through the development and subsequent implementation of the Program for the Integrated Development of Transport Infrastructure (PIDTI). How correct is it? Can the development and subsequent implementation of PIDTI to respond to challenges of the city, which forms the future? An attempt to answer this question using the example of a Tyumen case was made within the framework of this article. The purpose of the research was to identify the conformity of the decisions of the PIDTI of the Tyumen agglomeration $(2018 \ldots 2040)$ to the current and potential needs of the citizens. The objectives of the research were formulated as follows.

- Analysis of the development goals of Tyumen (Russian Federation) for the period up to 2040 (according to the PIDTI);

- Analysis of the current and potential needs of the residents of Tyumen;

- Analysis of production and financial opportunities to achieve the development goals of the city of Tyumen, declared in PIDTI;

- Analysis of the development goals of the transport and technological system of Tyumen for the purposes of the development of the urban area; conformity assessment between them;

- Identification of contradictions in the ideology of the PIDTI of Tyumen;

- Formulation of tasks for correction the PIDTI of Tyumen.

\section{Materials and Methods}

In accordance with the fundamental regulatory documents [10-14], the Department of Road Infrastructure and Transport of the Tyumen City Administration announced a competition for the development of a draft Program for the integrated development of transport infrastructure for the city district of Tyumen for the period 2018 ... 2040 (PIDTI) [15]. The competition was won by the Institute of Territorial Planning "Grad" (Omsk). During 2016 ... 2018 the employees of this company carried out work on the development of PIDTI in Tyumen. Further materials for writing this article were developments on this Project.

The main method of solving the tasks was chosen as a method of critical thinking about the proposed design solutions and comparing proposals with the subjective opinion of two groups of respondents.

The first group of respondents is two dozen urban planners and transport specialists who have lived in Tyumen for at least $35 \ldots 40$ years and have specialized production experience. The second group of respondents - residents of Tyumen - participants of the exchange of views in the social networks of the Internet (hereinafter - the inhabitants). The collection of information from the respondents of the first group was carried out in the form of direct conversations. For the second group of respondents, statistics and a general tone of opinions about PIDTI private design solutions were taken into account.

\section{Data}

\subsection{The purpose and objectives of the development of transport infrastructure of Tyumen for the period up to 2040 (according to the PIDTI)}

The purpose of the PIDTI is the formation of an optimal set of measures for the construction and reconstruction of local transport infrastructure facilities aimed at creating a 
sustainable transport system in the territory of the city of Tyumen, ensuring the safety, quality and efficiency of transport services to the population.

Objectives of the PIDTI (as of 2018/2040):

- Reducing the time spent on the implementation of transport correspondence (time spent on one movement - $34.3 \mathrm{~min}$. / $35 \mathrm{~min}$ ).

- Increasing the availability of services provided by the urban passenger transport (the share of movement on the UPT of the total number of movements - 40\% / 50\%).

- Improving road safety (annual number of accidents - 1410/1108).

- Development of a local street and road network in the territories of low-rise residential buildings, multi-storey residential buildings, public and business buildings, utility and storage areas (the share of roads with capital coverage is $65 \% / 100 \%$ ).

- Development of the road network to gardening and country non-profit associations of citizens (the share of roads with capital coverage is $42 \%$ / 100\%).

- Development of a network of bicycle paths (total length - $41 \mathrm{~km} / 453 \mathrm{~km}$ ).

- Creation of favorable conditions for pedestrian traffic (share of implemented activities $-7 \% / 100 \%)$.

- Creation of conditions for the development of a united parking space (the number of places for storing vehicles is $150000 / 412075$ ).

- Financial support for the development of transport infrastructure (the volume of investment in the transport infrastructure for 1 person per year is 7 thousand rubles / 9 thousand rubles).

\subsection{Description of the planned activities in the plans of the PIDTI of Tyumen (for the period up to 2040) and target indicators}

\subsubsection{General vision of city development plans}

The PIDTI of Tyumen noted the expectation that by 2040 the projected population of the city of Tyumen for the target option will be 1300 thousand people. In figure 1 shows the plans for the development of the territory of the city with a breakdown by periods 2017 ... 2020. (zones marked in yellow); 2021-2025 (zones marked in green); 2026-2040 (zones marked in dark blue).

The average number of people employed in the economy of Tyumen in 2017 amounted to 424 thousand people. By 2040, it is expected that no less than 200 thousand new jobs will be created in the territory of the urban district, while the total number of people employed in the city's economy may reach the level of 600 thousand people. Of this number, about $2 / 3$ will work in the provision of services. 


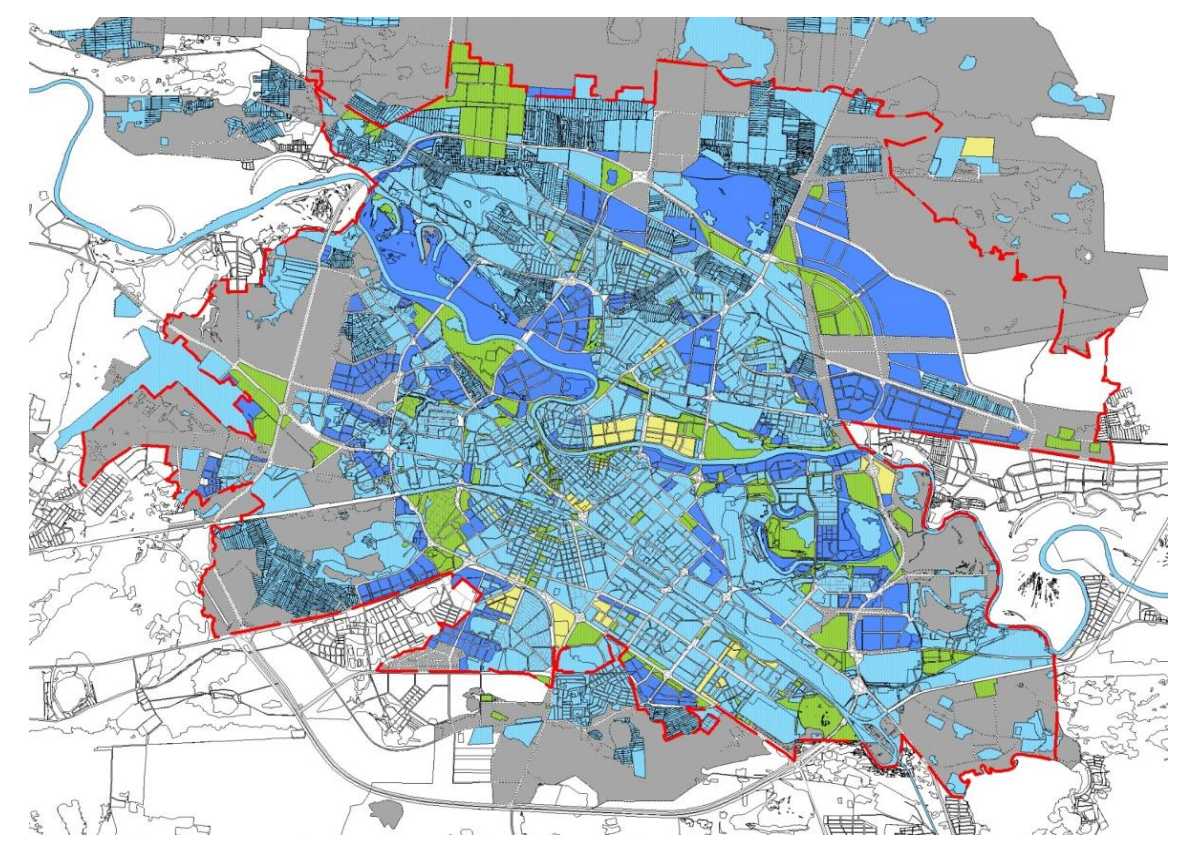

Fig. 1. Plans for the development of the territory of Tyumen (2018 ... 2040) [15].

\subsubsection{Activities for the development of the public transport, the creation of transport hubs}

- Construction of public passenger transport stopping points - 592 objects.

- Construction of final stops for public passenger transport with a platform for parking of vehicles - 33 objects.

- Construction of off-street public passenger transport lines $-51.8 \mathrm{~km}$.

- Construction of a depot of off-street public passenger transport - 1 object.

- Construction of transport hubs - 10 objects.

3.2.3 Activities for the development of infrastructure for passenger cars, including the development of a united parking space

- Construction and reconstruction of permanent storage facilities for passenger vehicles 262,000 parking places.

\subsubsection{Activities for the development of the network of roads of Tyumen}

- Construction and reconstruction of the reference road network - $329.3 \mathrm{~km}$.

- Construction and reconstruction of streets in low-rise residential buildings $-472.8 \mathrm{~km}$.

- Construction and reconstruction of entrances to gardening, country non-profit associations of citizens $-77.4 \mathrm{~km}$.

- Construction and reconstruction of streets in areas of public and business, high-rise residential buildings $-274.1 \mathrm{~km}$.

- Construction and reconstruction of streets in production and storage areas $-56.6 \mathrm{~km}$.

- Construction of tunnels and road junctions to increase the capacity of intersections through natural and artificial obstacles - 42 objects. 


\subsubsection{Activities for the development of infrastructure for walking and cycling}

- Construction of bike lanes - $412 \mathrm{~km}$.

- Construction of pedestrian crossings in different levels with a carriageway - 233 objects.

- Construction of pedestrian streets - 56 objects.

\section{Justification of target and planned indicators PIDTI}

The values of the target indicators of the PIDTI of Tyumen are determined by calculating using the software MapInfo, PTV VISUM, taking into account the provisions of SP 42.13330.2016 Urban planning. Planning and development of urban and rural settlements. Updated version of SNIP 2.07.01-89 [16], the requirements of regulatory and technical documents in force in the territory of the Russian Federation, regional and municipal programs for the construction, reconstruction of transport infrastructure facilities in the territory of the city of Tyumen.

\subsection{Volumes and sources of PIDTI funding}

A total of 2018 ... 2040 years The Program provides for 546860.5 million rubles for the implementation of measures, including by sources of funding:

1. Budget funds - 341090.5 million rubles:

- the federal budget - 9883.9 million rubles;

- budget of the Tyumen region -115490.5 million rubles;

- budget of the city of Tyumen - 215716.1 million rubles.

2. Extrabudgetary funds -205770.0 million rubles.

\section{The results of the discussion of the stated plans of the PIDTI and critical understanding of the possibilities of their implementation by specialists and ordinary people}

\subsection{Critical understanding of the goals and objectives of PIDTI of Tyumen}

All respondents (specialists and ordinary people) noted the correctness of the purpose and objectives of the PIDTI. However, the fundamental difference between the views of representatives of the two groups was in a different in-depth understanding of the goals. Specialists focused on the priorities of public transport development, and the inhabitants formed their idea around the benevolent pictures of the seamless use of individual cars. Experts expressed doubt in the reality of achieving the set quantitative indicators; the philistines showed optimism.

\subsection{Analysis of production and financial capabilities to achieve the development goals of the city of Tyumen, declared in the PIDTI}

First of all, it should be noted that the detailed planning of both finance and the list of specific activities for a period of 20 years or more caused confusion among all respondents (specialists and ordinary people). Forecasting specialists, first of all S. B. Pereslegin [1], note that today there is no way to anticipate in detail the technological changes that await us in the future. We can assume only the direction of these technological changes. Even more relevant is the bewilderment regarding the long-term forecasting of the production and 
financial capabilities of a country, region, city. The practice of three-year planning, adopted today in the Russian Federation, gives a systemic failure, and experts note this [17].

Focusing on the current levels of resource provision of the city of Tyumen [18], it can be argued that the current level of budget provision of the city itself does not allow solving the tasks stated in the PIDTI. In particular, for 2019, budget revenues for the city of Tyumen are projected at 25.3 billion rubles, expenses -27.4 billion rubles. It is planned to spend for the entire term of 215.7 billion rubles for the implementation of the tasks of the PIDTI from the budget of Tyumen or about 10 billion rubles per year, which is about $40 \%$ of the total budgetary support for the life of the city (as of 2018... 2019). In addition, according to PIDTI, it is planned to attract 205.8 billion rubles extrabudgetary funds, which also raises great doubts.

\subsection{Analysis of the compliance of the development tasks of the transport and technological system of Tyumen with the objectives of the development of the urban area}

Ordinary people agreed that the tasks are ambitious and positive; approved these tasks. At the same time, many were surprised that the required investment in transport infrastructure to achieve these objectives should be increased only by $30 \%$ (from 7 thousand rubles to 9 thousand rubles for 1 person per year).

Experts noted the eclectic and contradictory stated tasks. In particular, the following inconsistencies were noted.

- It was noted that the authors of the PIDTI are betting on the development of both public and individual transport at the same time. The tasks of the PIDTI contain a contradiction between the ecological and technological trends in the development of the city.

- Also, experts noted that the 2040 targets are not being improved compared to the baseline. Thus, the time spent on one movement is projected in 2040 at the same level as in 2018; the annual number of accidents is planned to be reduced in the future by only $20 \%$, despite the fact that by 2040 autonomous unmanned transport systems will function all over the world, the safety of which will be one or two orders of magnitude higher (up to $30 \ldots$ 100 times).

- It was separately stated that there is a contradiction in the PIDTI between the goals of the development of parking space (the priority of developing individual vehicles) and cycling (individual vehicles must be in a bad position).

\section{Discussion. Identification of contradictions in the ideology of the PIDTI of Tyumen}

Comprehending the opinions of respondents regarding theses of the Program for the Integrated Development of the Transport Infrastructure of Tyumen (2018), one can come to the following basic conclusions.

- PIDTI of Tyumen (2018) is an internally contradictory document; This document does not answer the question of how Tyumen will be a city - "for individual automobilist" or for "users of public and environmentally friendly forms of transport"?

- PIDTI of Tyumen (2018) and the implementation of even some of the tasks will not at least partially reduce the severity of the transport problem in the city.

- PIDTI of Tyumen (2018) is not a development document, but rather, on the contrary, an obstacle to this development. This conclusion is based on the extremely low probability of implementation in the practical plane of the stated tasks. Due to the fact that it is 
impossible to perform super-ambitious tasks, small but realistic tasks will most likely not be carried out.

- PIDTI Tyumen (2018) is a project document, which contains unreasonable dreams, for the realization of which there is no reasoned objective basis.

In order to argue such disappointing conclusions (in particular, conclusion № 2), we give an example of one of the particular solutions of PIDTI of Tyumen (2018). PIDTI recommends the construction of three overpasses on the Melnikayte st. (one of the most important streets of the city in the cross section of the urban area) on the transport hubs formed by the intersection of this street from 30 let Pobedy st., Respublica st., 50 let Octyabrya st. This section of Melnikayte st. has a length of $2.1 \mathrm{~km}$.

According to the simulation modeling carried out on PTV Vissim [19], the overpasses planned for construction will significantly improve the traffic situation (Table 1) at that section of Melnikaite st. that adopted as an experienced (length $2.1 \mathrm{~km}$ ).

However, it does not take into account that the imitation of the transport situation should have been lost for the entire length of the Melnikaite st. (with a total length of about $9.5 \mathrm{~km}$.), on which there are at least 6 traffic lights in the plane of the road. This was not done, and in this regard, the simulation results are not adequate to the real situation. In case modeling is carried out for all transport hubs of Melnikayte st., then the above gain in speed will not. Average speed on the Melnikayte st. will remain at the level of $9.5 \ldots 10 \mathrm{~km} / \mathrm{h}$, while in some of its sections it will reach $15 \mathrm{~km} / \mathrm{h}$, and on others - only $5.5 \ldots 6 \mathrm{~km} / \mathrm{h}$.

Table 1. The results of simulation modeling of the movement time traffic flows using the three planned for construction overpasses on the Melnikaite street in the city of Tyumen.

\begin{tabular}{|c|c|c|c|}
\hline \multirow[b]{2}{*}{$\begin{array}{l}\text { Traffic parameters for } \\
\text { morning time }\end{array}$} & \multicolumn{2}{|c|}{ Parameter Value } & Relative change \\
\hline & $\begin{array}{c}\text { Existing } \\
\text { option } \\
(2018)\end{array}$ & $\begin{array}{l}\text { Option with three } \\
\text { overpasses }\end{array}$ & \\
\hline Average delay time, sec & 159 & 98 & $-38 \%$ \\
\hline Average speed, km / hour & 9,6 & 15,3 & $+60 \%$ \\
\hline The length of the queue, cars & 1401 & 531 & $-62 \%$ \\
\hline Relative time delay, $\%$ & $100 \%$ & $55 \%$ & $-45 \%$ \\
\hline \multicolumn{4}{|c|}{ The journey time on the site $2.1 \mathrm{~km}$. - from the 30 let Pobedy st. to the 50 let Oktyabrya st. } \\
\hline Travel time, sec & 788 & 494 & $-37 \%$ \\
\hline $\begin{array}{l}\text { Total cost of the project, } \\
\text { million rubles }\end{array}$ & 0 & $\approx 15000$ & $\infty$ \\
\hline
\end{tabular}

Speaking this situation, both with specialists and with ordinary people, we were inspired by the fact that all respondents understand the fallacy of choosing a strategy for converting an ordinary city street to highway status. However, experts at the same time advised to use the streets - chords in peripheral areas of the city as a highway. In most cases, ordinary people found it difficult to choose any other alternative options for increasing the speed of traffic flow.

Thus, the Tyumen PIDTI (2018) does not ask about the strategic choice of the best option for the urban transport and technological system, but is only a beautiful form of presenting the previously resolved issue of investing serious finances in urban projects that are interesting to particular groups of biased performers.

\section{The tasks of correction PIDTI of Tyumen}

In the works [20-21] the specific issues of optimizing future work on improving the transport and technological system of Tyumen are considered. In the [20], considerations are presented on the specifics of the implementation of the general plan for the Tyumen 
agglomeration. In particular, the results of simulation modeling of the functioning of individual sections of the road network in the city of Tyumen are presented. The obtained results should be taken into account when correcting individual decisions of the PIDTI. In the [21] even more interesting results are presented, in particular, conclusions about changes in traffic flow patterns under conditions of changing road conditions during the winter period, during precipitation and other non-standard variants of the negative impact on the transport complex of the environment. Using these developments, it is possible to adjust both the target settings of the PIDTI and the approaches professed by the authors of this program document.

Consolidated tasks for the correction of PIDTI of Tyumen can be formulated as follows.

- It is necessary to determine the priorities of the strategic development of the city and answer the question "Is the Tyumen-2040 a city for a car or for a person?".

- It is necessary to once again calculate the consistent and objectively possible values of the planned characteristics for the development tasks of the transport and technological system of Tyumen.

- It is necessary to once again calculate the economy of PIDTI; determine how realistic the implementation of the tasks formulated in PIDTI.

\section{Conclusion}

For the modern Russian Federation is characterized by a bias towards excessive regulation of almost all aspects of the public life. S.B. Pereslegin [1] notes that today there are about 1 million regulatory documents in force in Russia, which are not something to execute, but even to know fully impossible. Today, the Russian state is developing and putting into operation tens of thousands of regulatory documents per year. Obviously, this is a kind of compensation for those omissions that were made in the 1990s. However, despite the obvious advantages of the practical use of regulatory support in forecasting the future, this process also has obvious drawbacks. For PIDTI these are the following omissions. The main thing, of course, is that there should be no conceptual and dialectical contradictions in such strategic documents as PIDTI. Secondly, the long-term planning documents, to which the PIDTI belongs, practically do not take into account the trends of revolutionary technological changes. Thirdly, changes in the lifestyle of citizens are not taken into account, which of course will occur due to another change in the technological structure [1]. Fourth, economic calculations are based on the current situation, and experience shows that over the course of 20-25 years, there will almost certainly be major changes in the economy.

In conclusion, we are still optimistic about the significant positive changes in the development of the transport and technological complex of Tyumen, and these have occurred in the last $(2000 \ldots 2018)$ years. Even in the absence of PID.TI, the tasks of improving the road transport infrastructure of the city were solved, and successfully solved. This causes optimism.

\section{Reference}

1. S.B. Pereslegin, New maps of the future or Anti-Rand (AST: Terra Fantastica, Moscow, 2009)

2. V.L. Glazychev, The political economy of the city (Delo, Moscow, 2009)

3. G.P. Schedrovitsky, Selected Works (School of cultural policy, Moscow, 1995)

4. G. Higgs, S. White, Alternatives to Census-Based Indicators of Social Disadvantate in Rural Communities (Progress in Planning, 2000) 
5. H. Hoering, M.L. Seasons, Planning, Practice and Research 19, 1 (2004)

6. R. Florida, Cities and the Creative Class (Routledge, 2005)

7. E. Glaeser, Triumph of the city (The penguin press, New York, 2011)

8. Federal Law of Russian Federation № 131-FZ

9. Decree of the Government of the Russian Federation № 1440

10. Russian Federation Standard SP 42.13330.2016

11. D. Zakharov, E. Magaril, E. C. Rada, Sustainability 10, 2052 (2018) 